\section{Visual pattern perception: Multidimensional analysis of discrimination difficulty for children*}

\author{
LYNNE F. HARRINGTON and D. R. BROWN \\ Purdue University, West lafayette, Ind. 47907
}

Five- and 6-year-old children were tested on three-choice oddity problems constructed from pairs of patterns which were selected to be perceptually two-dimensional. Lsing nonmetric multidimensional scaling techniques, discrimination latencies were analyzed. Meaningful and reliable euclidean solutions were obtained in two dimensions for group data and for four of six individual children.

During the last decade, considerable work has been directed toward developing a psychophysics of visual pattern perception (e.g., Brown \& Owen, 1967; Evans, 1967; Zusne, 1971). This work has been characterized by the application of multivariate statistical techniques to the problem of mapping visual patterns, which are viewed as multidimensional in nature, into perceptual responses, which are viewed as multidimensionally determined. Applied to adult perception, this approach has generated encouraging results. It has been possible, for instance, to account for a reasonable proportion of the variance in perceived complexity (Owen \& Brown, 1970), discrimination difficulty (Brown \& Andrews, 1968), perceived similarity (Behrman \& Brown, 1968), and perceived class membership (Aiken \& Brown, 1971a, b; Mavrides \& Brown, 1970 ) from quantified pattern dimensions.

Multidimensional scaling techniques have been found to be useful in this effort (Brown \& Andrews, 1968; Stenson, 1966). Most relevant to the purposes at hand, we followed Shepard's (1960) suggestion to use discrimination latency as a measure of similarity to determine distances among stimuli in a multidimensional response space (Brown \& Andrews, 1968) and obtained results that were highly similar to those obtained from judgments of perceived similarity (Behrman \& Brown, 1968) for adult Ss. The research reported herein was designed to evaluate the applicability of these techniques to the study of perception with children. Visual pattern research, using young children as Ss, has been summarized elsewhere (e.g., Gibson, 1970; Zusne, 1971). An analysis of this work indicates that

\footnotetext{
* This research was supported by Research Grant HD-00909 from the National Institute of Child Health and Human Development.
} problems was obtained as the 6 pattern pairs. For each pair, one pattern was randomly selected as "correct" and the other pattern was reproduced to form the problem. The basic set of problems was then expanded to 45 problems by moving the correct pattern through the three possible positions. Using the other pattern as "correct," a second set of 45 problems was constructed by the same procedure.

APPARATUS AND PROCEDURE

Testing was preceded by $30 \mathrm{~min}$ of instruction and training designed to assure that each $S$ recognized all of the individual patterns and fully understood the nature of the problems and task.

Problems were presented on the front of a 20-in.-sq wooden screen. Embedded in the screen were three Plexiglas windows covering projection readouts. The readouts were $2.5 \mathrm{in}$. sq and were spaced 2 in. apart in a horizontal linear array. On each trial, $E$ selected a problem, gave a "ready" signal, and presented the problem with a startswitch, which projected the problem and started two millisecond timers. When the $S$, who had been instructed to depress the correct Plexiglas cover as quickly as possible, made the correct choice, the display was extinguished. When an error was made, the display remained on until a correct response was made. Both the correct and error latencies were recorded.

Order effects were controlled by assigning the days to columns, children to the rows, and the six sets of problems to the cells of a 6 by 6 Latin

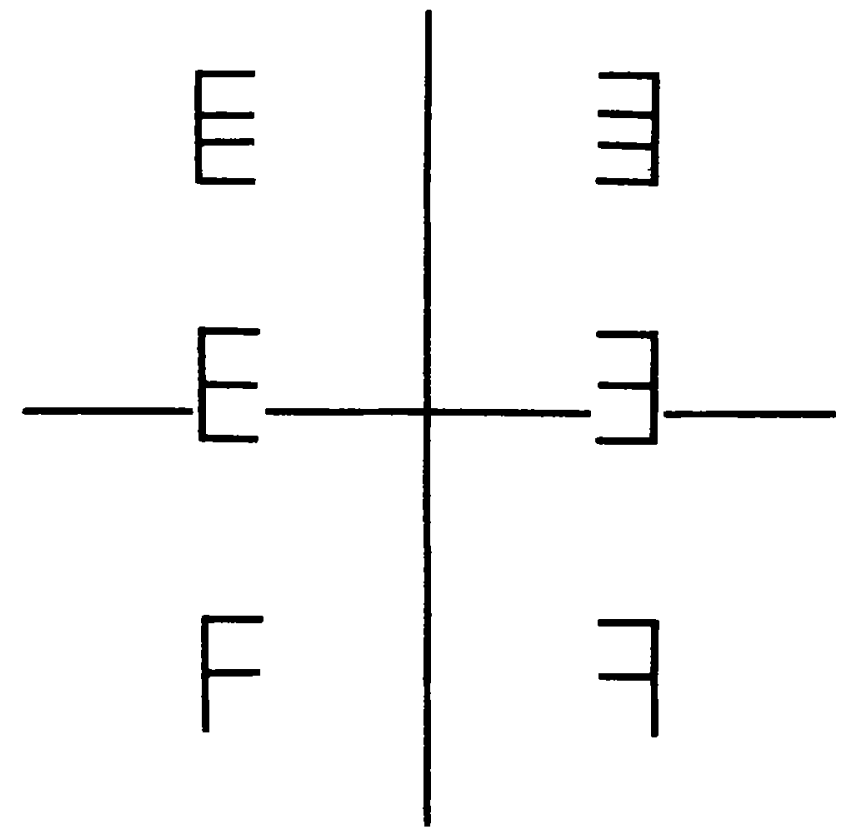

Fig. 1. Stimulus patterns used to generate three-choice oddity problems. 


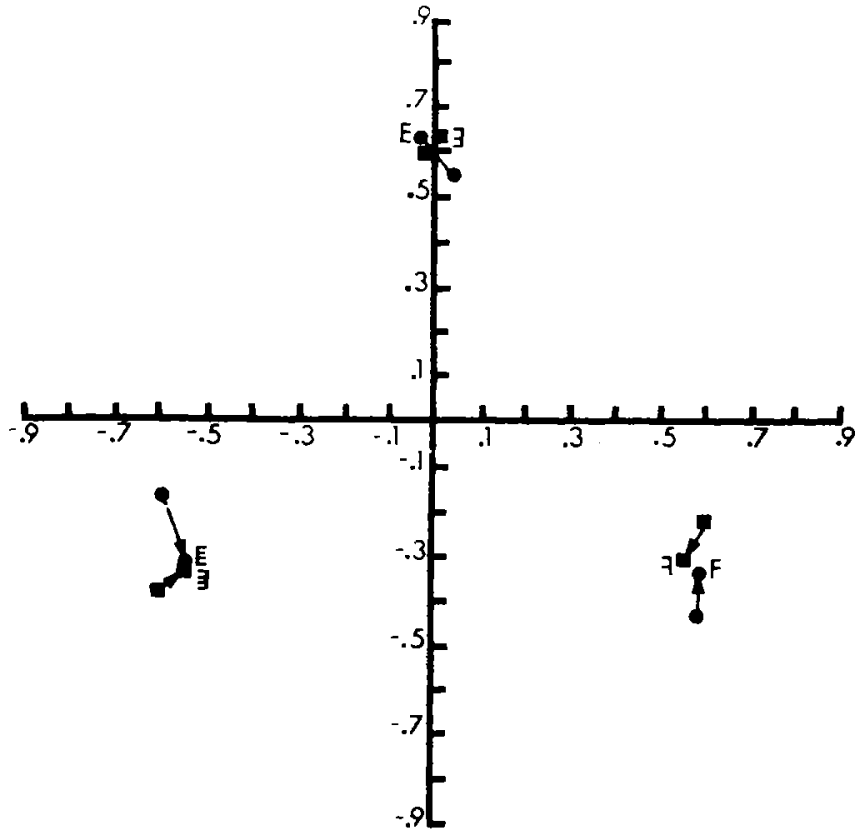

Fig. 2. Two-dimensional euclidean solution averaged over Os. Arrows indicate change of position for individual patterns from Replication 1 to Replication 2.

square. Ss were tested individually with the 15 problems independently randomized each day. The entire set of 90 problems was repeated by the same procedure and design to determine reliability.

Very few errors were made. Consequently, error trials were randomly repeated in the sequence of each day's testing and latencies of all responses were analyzed.

\section{RESULTS}

Latencies were treated as similarity estimates and analyzed by nonmetric (Kruskal, 1964a, b) multidimensional scaling methods. The logic of this analysis is simply the assumption that the more similar two stimuli are, the longer it should take to discriminate them. There is evidence that this is true even when stimuli are quite different (Woodworth \& Schlosberg, 1954). Further, nonmetric analyses require only that similarity estimates be monotonically related to distances in the solution space.

Solutions were generated in one and two dimensions with the euclidean model $(r=2.0)$ for the data of individual $\mathrm{Ss}$ and for mean latencies of all Ss for the first and second replication of the 90 problems. For both group and individual $S$ data, this averaged latencies over positions in the problems and correct patterns. The average solution for all $\mathrm{Ss}$ is presented in Fig. 2 in two dimensions. The stress values for the first replication were .510 and .011 for one- and two-dimensional solutions, respectively; for the second replication, they were .328 and .001 .
Spatial solutions for individual ss were generated in order to evaluate the extent to which reliable and meaningful data for each $S$ could be obtained. Two patterns emerged from the individual $\mathbf{S}$ solutions: apparently random results (two $S s$ ) and results highly similar to Fig. 2 (four Ss). Two of the latter solutions are shown in Figs. 3 and 4 . The solution in Fig. 3 is almost identical to the group solution and was obtained in two dimensions with stress equal to .071 . The solution shown in Fig. 4 was characteristic of three of the four reliable Ss and was obtained in two dimensions with stress equal to .069 . It is displayed here to demonstrate the sensitivity of solutions to learning over replications. This is evidenced by the fact that the mirror images of all patterns became more discriminable during the second replication and by the fact that the degree to which this occurred was related to pattern complexity, an intuitively appealing result.

\section{DISCUSSION}

We find obtaining reliable and interpretable results for individual Ss highly encouraging. There are a number of significant areas of research in which one would like some estimate of what the perceptual world "looks like" to children prior to an age at which they reliably respond to complex verbal instruction. For instance, the extent to which basic visual pattern perception skills are related to developing reading skill is almost totally unknown. There are neurophysiological data accumulating
In both solutions, then, two-dimensional configurations gave llent fits to the latenc Moreover, Fig. 2 makes it clear that over replications and that interpretable results were obtained-the three levels of complexity were equally discriminable and the mirror images were equally difficult to discriminate at each level of complexity.

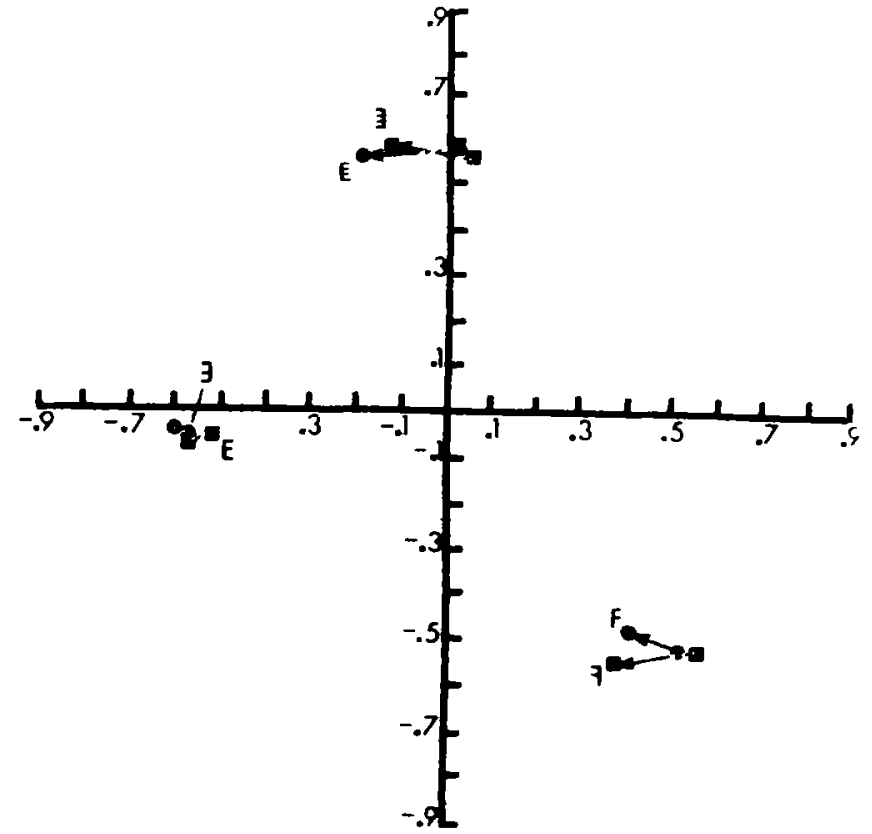

Fig. 3. Two-dimensional euclidean solution for a single $O$ most similar to the group solution. 


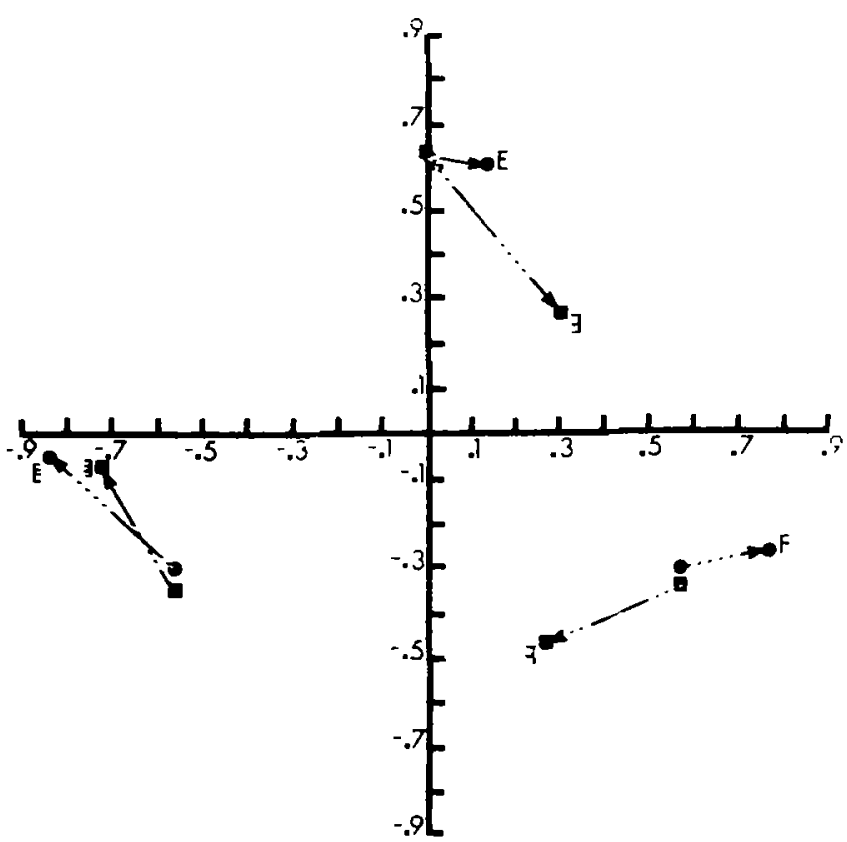

Fig. 4. Two-dimensional euclidean solution for a single $O$ reflecting learning.

with subhuman Ss (see Dodwell, 1970, for instance, for an excellent summary of this work) and psychophysical data collected with human observers (e.g., Weisstein, 1969) which are beginning to clarify the nature of pattern analysis at central levels of the visual system. Those data may provide a basis for selecting patterns and units of patterns that are meaningf 1 l in torms of how the visual system processes patterned inputs. Applying methodologies such as that described herein to the perception of carefully chosen pattern classes by young children may help provide a basis for

understanding the normal and complex skills, such as reading.

\section{REFERENCES} 145-149. Psychophysics, 1971b, 9, 279-283.
BEHRMAN, B. W. \& BROWN D. R Multidimensiona' scaling of form: A psychophysical analysis. Perception \& Psychophysics, 1968,4,19-25.

BROWN, D. R. \& ANDREWS M H Visual form discrimination: Multidimensional analyses. Perception \& Psychophysics, $1968,3,401-406$.

BROWN D. R. \& OWEN D $H$ The metrics of visual form: Methodological dyspepsia. Psychological Bulletin, 1967, 68, 243-259.

DODWELL, P. C. Visual pattern recognition. New York: Holt, Rizebart \& Winston. 1970 .

EVANS. S. H. Redundancy as a variable in pattern perception. Psychological Bulletin, 1967a, 67, 104-113.

GIBSON, E. J. Principles of perceptual learning and development. New Yodk: Appleton-Century-Crofts, 1969.

KRUSKAL, J. B. Multidimensional scaling by optimizing goodness of fit to a nonmetric hypothesis. Psychometrika, $1964 a, 29,1-27$.

KRUSKAL.J. B. Nonmetric multidimensional scaling: A numerical method. Psychometrika, 1964. 29. 115-129.

MAVRIDES, C. M., \& BROWN, D. R Schematic concept formation: Feature measures and constraint redundancy as predictors. Perception \& Psychophysics. 1970, 7, 239-243.

OWEN, D. H., \& BROWN, D. R. Visual and tactual torm complexity: psychophysical approach to perceptual equivalence. Perception \& Psychophysics. 1970. 7, 225-228. abnormal development of pattern processing and its relation to more

AIKEN, L, S., \& BROWN, D. R. Feature utilization of continuously varying attributes in visual pattern classification. Perception \& Psychophysics. 1971a,9.

AIKEN, L. S.. \& BROWN, D. R. A feature utilization analysis of the perception of pattern class structure. Perception \&

SHEPARD, R. N. Similarity of stimuli and metric properties of behavioral data In $H$. Gulliksen and $S$. Messick (Eds.), Psychological scaling: Theory and applications. New York: Wiley, 1960.

STENSON, $H$. $H$. The physical factor structure of random forms and their judged complexity. Perception \& Psychophysics, 1966, $1,303-310$.

WEISSTEIN, $N$. What the frog's eye tells the human brain: Single cell analyzers in the human visual system. Psychological Bulletin, 1969, 72, 157-176.

WOODWORTH, R. S., \& SCHLOSBERG, H. Experimental psychology. New York: Holt, Rinebart \& Winston, 1954

ZUSNE. L. Visual perception of form New York: Academic Press, 1970. 